\title{
MELHORIA NO PROCESSO DE TINGIMENTO DE FIBRAS DE POLIÉSTER APÓS HIDRÓLISE POR ENZIMA LIPASE
}

\author{
Assis AHC ${ }^{*}$, Munaro $\mathrm{M}^{* *}$
}

\section{Resumo}

As fibras de poliéster possuem diversas aplicações na confecção de tecidos. O processo de tingimento consiste na etapa para a fixação de cor à fibra. Há três formas nas quais os materiais têxteis podem ser tingidos: em massa, na forma de fio e na forma de tecidos; sendo o tingimento dos fios o mais utilizado por possibilitar uma maior diversificação e solidez das cores. O consumo de água nessa etapa é bastante significativo, e a cor forte é a característica mais notória do efluente têxtil, consequência da grande quantidade de corantes não fixados durante o tingimento. Políticas ambientais incentivam o desenvolvimento de novas tecnologias que prezem pela sustentabilidade. As enzimas são produtos naturais encontrados no corpo humano e na natureza e agem de forma bastante específica; por essa razão desempenham papel fundamental na indústria têxtil, como na substituição de produtos químicos que têm impacto negativo sobre o meio ambiente. A utilização de enzimas proporciona variações superficiais nas fibras, em decorrência da formação de grupos carboxílicos, os quais facilitam o tingimento. No presente trabalho se investigou a hidrólise de fibras de poliéster para otimização do processo de tingimento por esgotamento. Foi realizada análise comparativa da hidrólise superficial por tratamento enzimático e alcalino para análise da formação de grupos ácidos, melhoria na fixação de corantes e diminuição da carga orgânica do efluente gerado. As mudanças na estrutura e propriedades dos materiais foram analisadas por intermédio de ensaios mecânicos, microscopia eletrônica de varredura (MEV), espectroscopia de infravermelho com transformada de fourier (FTIR), análise dinâmico-

\footnotetext{
* Mestre em Engenharia pela Universidade Federal do Paraná; Professora do Programa de Pós-graduação em Engenharia e Ciências dos Materiais na Universidade Federal do Paraná; adri_coleto@yahoo.com.br

** Doutora em Engenharia e Ciências dos Materiais pela Universidade Federal do Paraná; Professora do Programa Pós-graduação em Engenharia e Ciências dos Materiais na Universidade Federal do Paraná; marilda@lactec.org.br
} 
-mecânica (DMTA), espectroscopia de reflectância e análise de absorbância em espectrofotômetro. O tratamento por hidrólise mostra-se uma alternativa viável, possibilitando aprimoramento do processo de tingimento por meio da diminuição da demanda química de oxigênio, variação dos sítios ácidos e variação no consumo de corantes.

Palavras-chave: Fibras de PET. Tratamento químico. Degradação. Tratamento de efluentes.

\title{
Improvement in the process of polyester fiber dyeing after hydrolysis by enzyme lipase
}

\begin{abstract}
The polyester fibers have many applications in the fabrics manufacturing. The dyeing process consists in the fiber color-fixing step. There are three ways in which the textile materials can be dyed, by mass, in the form of threads and in the form of fabrics; but the dyeing of the threads is the most used for enabling a greater diversity and strength of colors. Water consumption in this step is very significant, and the strong color is the most striking feature of the textile effluent, a consequence of the large amount of non-fixed dyes during dyeing. Environmental policies encourage the development of new technologies that care for sustainability. Enzymes are natural products found in the human body and in the nature, they act quite specifically; therefore, they play a key role in the textile industry, as in the substitution of chemicals that have adverse impact on the environment. The use of enzymes provides superficial variations in the fibers, due to the formation of carboxylic groups, which facilitate dyeing. In this study, it was investigated the hydrolysis of polymer fibers for the optimization of dyeing process by exhaustion. In this study, superficial comparative analysis of the hydrolysis by enzymatic and alkaline treatment was carried out to analyze the formation of acid groups, improvement in the fixation of dyes and reduction of organic load of the effluent. Changes in the structure and properties of the materials were analyzed by mechanical testing, scanning electron microscopy (SEM), infrared spectroscopy with Fourier transform (FTIR), dynamic mechanical analysis (DMTA), reflectance spectroscopy and analysis of absorbance by spectrophotometer. The treatment by hydrolysis is shown as a viable alternative, enabling enhancement of the dyeing process by the reduction of the chemical oxygen demand, variation of acid sites and variation in consumption of dyes.
\end{abstract}

Keywords: PET Fibers. Chemical treatment. Degradation. Effluent treatment.

\section{INTRODUÇÃO}

Cada vez mais as fibras sintéticas estão presentes em artigos de vestuário, em especial fibras de poli (tereftalato de etileno), o tipo de poliéster mais usado em aplicações têxteis. Apesar das muitas propriedades vantajosas, as fibras de poliéster são de baixa flexibilidade, extremamente hidrófobas e dispõem de uma baixa taxa de recuperação de umidade, o que dificulta o seu beneficiamento e resulta em desconforto para o usuário se não devidamente tratadas. Essas fibras podem ser utilizadas puras ou em mistura com algodão, viscose, náilon, linho ou lã, em proporções variadas. Os tecidos resultan- 
tes prestam-se à fabricação de inúmeros artigos: camisas, camisetas, pijamas, calças, ternos, lençóis, cortinas, artigos automobilísticos, entre outros. No que diz respeito à produção e ao número de trabalhadores, a indústria têxtil é uma das maiores do mundo e caracteriza-se por requerer grandes quantidades de água, corantes e produtos químicos utilizados ao longo de uma complexa cadeia produtiva. ${ }^{1}$

O processo de obtenção de fibras de poliéster ocorre por extrusão via fusão. Trata-se de um método de fiação, que consiste em duas operações distintas: extrusão e estiramento. Na extrusão o polímero é aquecido até a temperatura de fusão, $260^{\circ} \mathrm{C}$, e o fundido é transportado mediante bomba com velocidade constante e pressão elevada, através de pequenos orifícios da fieira. A fieira (spinneret) é um disco de aço de espessura de 6,35 mm e diâmetro de 51-76 mm. Os orifícios da fieira possuem diâmetro de 0,25 mm ou menores e não são necessariamente circulares. Após, os fios são enviados para o processo de fiação convencional para obtenção de fios singelos. A partir de um fio singelo, é possível obter uma infinidade de efeitos no fio, com tantas combinações quanto necessário. O controle da taxa de resfriamento e a velocidade de fiação permitem obter fios com diferentes graus de orientação e densidade.

Após a fiação, as fibras são enviadas para o tingimento, que consiste em um processo de equilíbrio físico-químico, denominado difusão e sorção de moléculas de corantes ou íons. Esse fenômeno ocorre quando agentes presentes na dispersão aquosa ocasionam a adsorção por parte da partícula do corante finamente dividido sobre uma das várias interfaces do sólido. O poli (tereftalato de etileno) apresenta baixa polaridade, portanto não conta com forças de longo alcance que facilitariam a adsorção com o corante. Forças de curto alcance como Van der Waals e interações hidrofóbicas são as forças motrizes no processo de adsorção dessas fibras. ${ }^{2} \mathrm{O}$ procedimento é realizado em três etapas, nas quais ocorrem os seguintes processos de natureza físico-química: difusão, adsorção e fixação do corante. Para que ocorra o tingimento, inicialmente, o corante difunde do meio em que se encontra diluído para a superfície da fibra. Ocorre o contato do corante com a fibra e se inicia a adsorção pelas camadas superficiais. O corante se difunde para o interior da fibra e se fixa por meio de ligações iônicas, ligações de hidrogênio, forças de Van der Waals ou ligações covalentes, dependendo da natureza do material polimérico que a constitui e do tipo de corante empregado. ${ }^{3}$

O corante deve fazer parte integrante da fibra após o tingimento, a cor aplicada deve estar distribuída uniformemente em toda a extensão do material têxtil e deve resistir aos agentes desencadeadores de desbotamento, como lavagem, suor, água clorada, luz, etc. A modelagem aceita, a fim de ilustrar o mecanismo de tingimento, estabelece a presença de duas regiões distintas: região cristalina bastante densa, empacotada e orientada convivendo com regiões amorfas menos densas. A quantidade de regiões cristalinas e amorfas depende fortemente das razões de estiramento, bem como das condições de cristalização. ${ }^{4}$ Quanto maior a região amorfa, maior a penetração do corante ao interior da fibra. O aumento da temperatura facilita a difusão, pois ao ultrapassar a temperatura de transição vítrea o acesso até as zonas amorfas da fibra é facilitado, decorrente do aumento da energia cinética e da solubilidade dos corantes. ${ }^{5}$ 
O mecanismo de tingimento é complexo e separado por duas etapas. A etapa cinética, em que é determinada a velocidade de difusão e adsorção, e a etapa termodinâmica, que motiva a fixação do corante na fibra, sendo também conhecida por afinidade. ${ }^{3}$ As situações relacionadas com a cinética e a termodinâmica proporcionam uma padronização dos parâmetros de tingimento, como tempo, temperatura e pressão do processo. A baixa solubilidade, o acesso dificultado dos corantes dispersos na fibra pela estrutura cristalina e alta orientação molecular desta são os parâmetros que ditam o mecanismo de tingimento. ${ }^{6} \mathrm{O}$ subproduto desse processo é o chamado efluente têxtil, sendo a cor forte a característica mais notória do efluente deste, consequência da grande quantidade de corantes não fixados (entre 10 e 15\%) durante o tingimento, constituindo passivo ambiental, se não adequadamente tratado. ${ }^{7}$ Os efluentes gerados pelas indústrias têxteis passam por tratamentos físico-químicos e biológicos convencionais (coagulação química e lodos ativados), os quais apresentam bons resultados na redução de poluentes, possibilitando aos efluentes condições e padrões de lançamento ao corpo receptor em conformidade com os requisitos legais determinados pelo Conama n. 357/200. No entanto, esses tratamentos são caros e demorados.

O poliéster absorve apenas $4 \%$ de umidade e não intumesce em água; portanto, a falta de interação entre o polímero e o banho de tingimento obriga o uso de grandes quantidades de água e um sistema de alta temperatura/alta pressão, a fim de atingir velocidades de tingimento aceitáveis em nível industrial. Modificações superficialmente realizadas por meio da hidrólise podem otimizar o processo de tingimento, diminuindo o consumo de corantes e insumos, isso porque uma hidrólise superficial controlada pode aumentar o número de grupos carboxílicos superficiais, facilitando a adsorção de corantes dispersos durante o tingimento; o ideal é definir o melhor para esse processo.

A hidrólise consiste na reação de uma molécula de água com determinado grupo químico, com quebra de ligação e adição de oxigênio e hidroxila a cada grupo remanescente, podendo ser provocada por ação enzimática (hidrolases) ou por processo químico comum. ${ }^{8}$

O tratamento alcalino proporciona uma degradação controlada das fibras, o que possibilita mudanças na hidrofilidade. Sabe-se que a reação entre a solução aquosa de hidróxido de sódio e o poliéster é uma reação de hidrólise superfícial e não atinge o interior da fibra, ${ }^{9}$ porque um composto altamente ionizado, como o hidróxido de sódio, não se difunde em compostos pouco polares como o poliéster. ${ }^{10}$

Em meio alcalino, utiliza-se, normalmente, um hidróxido $\left(\mathrm{OH}^{-}\right)$como nucleófilo, em vez da água. $\mathrm{O}$ cátion da base completa a reação, por ser mais forte que os poucos íons de hidrogênio gerados pela ionização da água. Dessa forma, na hidrólise básica não é regra, como nas hidrólises ácida e neutra, a formação de quantidades iguais de finais carboxílicos e hidroxílicos, podendo gerar, no limite da degradação, um sal do ácido tereftálico. ${ }^{11}$

O ácido tereftálico (AT), produto da hidrólise, é um ácido relativamente fraco, de baixa solubilidade em água ( $19 \mathrm{mg} \mathrm{L}^{-1}$ a $25^{\circ} \mathrm{C}$ ). Entretanto, para a hidrólise em meio ácido o AT formado será insolúvel, e parte dele precipitará na superfície do PET, como mostrado na, enquanto na hidrólise em meio básico o AT é solubilizado na forma de tereftalato $\mathrm{TA}^{2-}{ }_{(\mathrm{aq})}$ solúvel, que permanece em meio aquoso. ${ }^{12}$ 


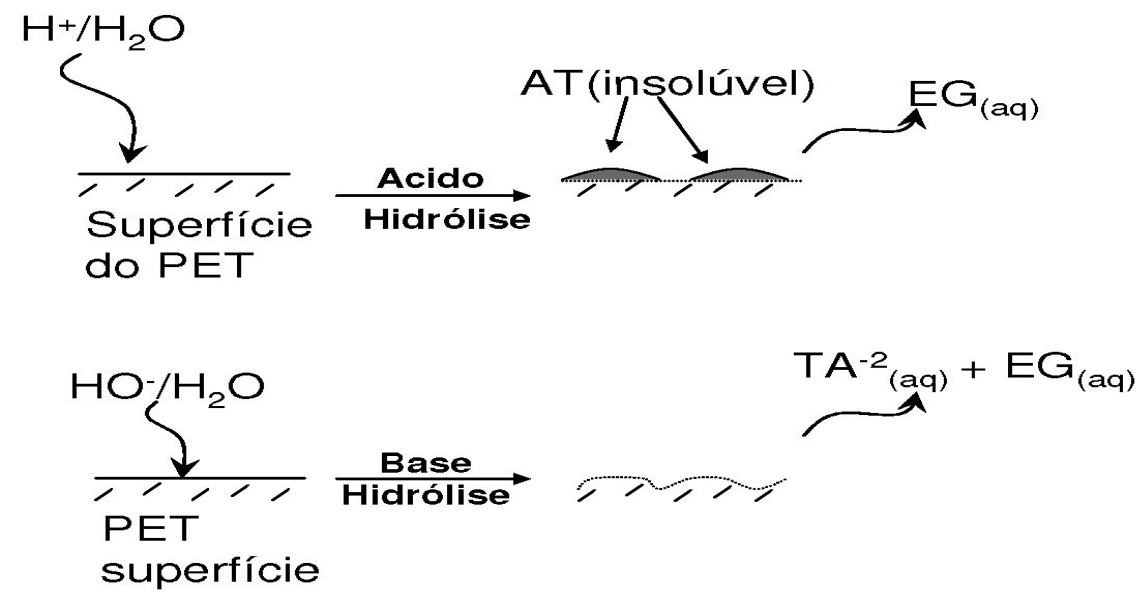

Figura 1 - Formação de ácido tereftálico após hidrólise do PET

Fonte: Rosmarinho et al. ${ }^{12}$

O mecanismo proposto para a degradação por hidrólise alcalina (-a) consiste em uma adição nucleofílica, com eliminação no carbono acila. O par de elétrons livres do oxigênio da hidroxila ataca o carbono da carbonila, com carga parcialmente positiva, resultando em um intermediário tetraédrico (-b). O oxigênio deficiente de ligações compartilha um par de elétrons com o carbono acila, que, por sua vez, expulsa um grupamento na forma de íon alcóxido (-c).O par de elétrons livres do oxigênio pertencente ao íon alcóxido ataca o hidrogênio, que possui carga parcialmente positiva. O hidrogênio é absorvido pelo íon alcóxido, fenômeno de prototropismo, o que leva à obtenção dos produtos finais (-d).

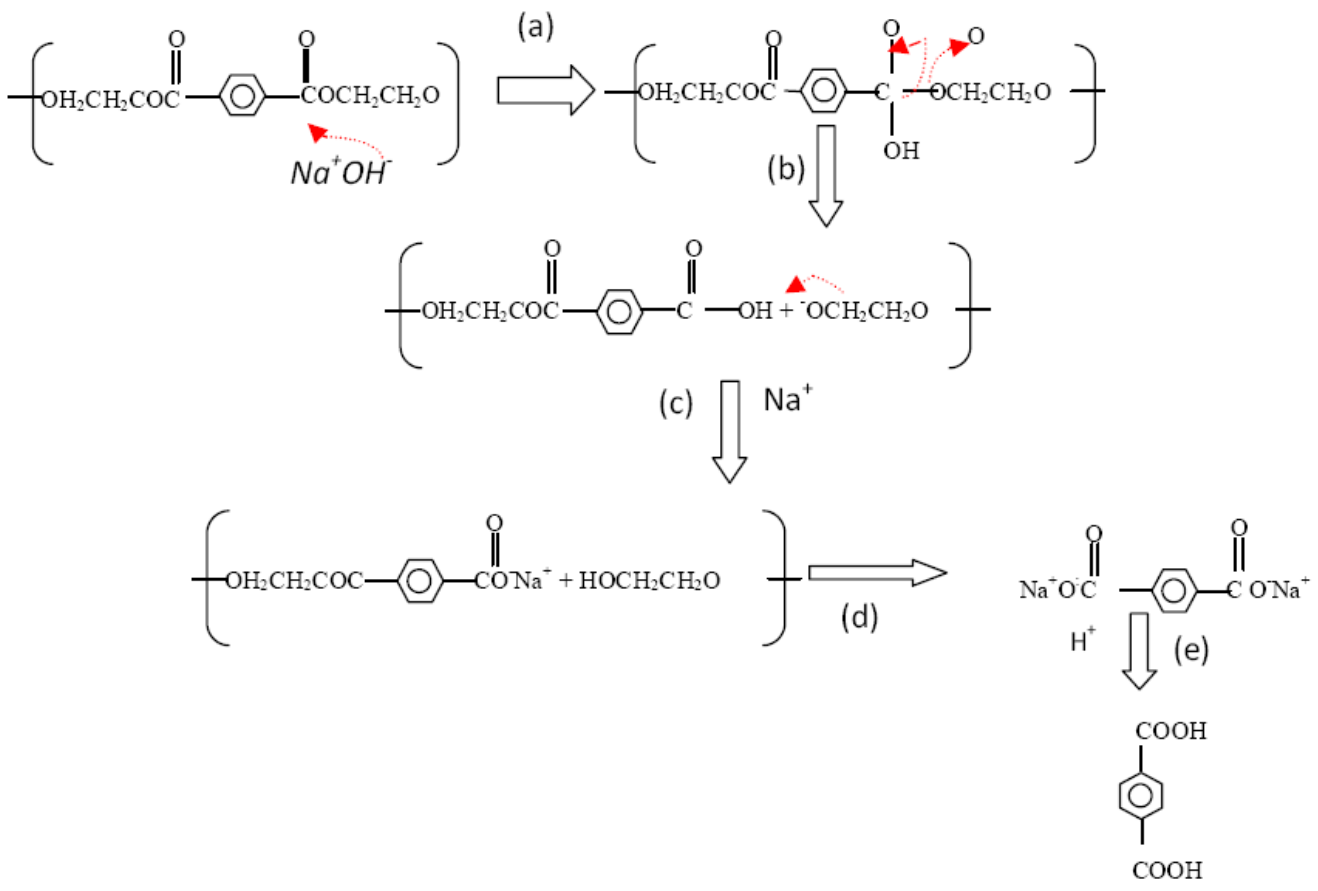

Figura 2 - Reação de hidrólise alcalina de poliéster † Fonte: Vogel. ${ }^{13}$

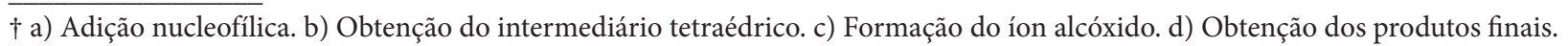


As enzimas hidrolíticas são muito utilizadas em síntese orgânica. Nesta classe estão incluídas as amilases, proteases, esterases, nitrilases, fosfatases e epóxido hidrolases, sendo de particular e grande interesse as lipases. ${ }^{14}$ As lipases (triglicerol acil-hidrolases, EC 3.1.1.3) são classificadas como hidrolases que agem sobre ligações ésteres presentes em acilgliceróis, liberando ácidos graxos e glicerol; essa catálise ocorre sobre substrato insolúvel em água. ${ }^{15} \mathrm{O}$ sítio catalítico é formado pela tríade Serina-Histidina-Aspartina, que se repete em todas as estruturas, sendo protegido na molécula por uma "tampa" hidrofóbica que, ao interagir com a interface lipídeo-água, sofre uma mudança, expondo o sítio ativo. ${ }^{16}$

A enzima utilizada para hidrolisar as fibras de poliéster é a Cândida Rugosa Triacylglycerol Lipase, de origem microbiana, com atividade média declarada de $724 \mathrm{U} / \mathrm{mg}$. Essa lipase atua na quebra das ligações éster, na estrutura do poliéster, provocando uma diminuição desses grupos e aumentando a presença de grupos hidroxílicos e carboxílicos. O mecanismo de hidrólise enzimática de ésteres é muito similar ao observado para a hidrólise química convencional utilizando hidróxido. Um grupo nucleofílico do sítio ativo da hidrolase ataca o grupo carboxílico do éster. Esse nucleófilo pode ser o grupo hidróxi da serina ou o grupo carbóxi do ácido aspártico ou ainda o grupo tiol da cisteína. ${ }^{17}$

O mecanismo elucidado em detalhes é o da serina. Dois aminoácidos localizados próximos à serina (geralmente uma aspartina e uma histidina) auxiliam na catálise e juntos formam a tríade catalítica. O arranjo espacial desses grupos favorece o aumento da nucleofilicidade do grupo hidroxila da serina, que pode, então, atacar um grupo carboxila de um substrato do tipo $\mathrm{R}_{1}-\mathrm{CO}-\mathrm{OR}_{2}(-\mathrm{a})$. Dessa forma, o intermediário acil-enzima é formado liberando o grupo de saída $\left(\mathrm{R}_{2}-\mathrm{OH}\right)$. Em seguida, um nucleófilo (em geral a água) ataca o intermediário acil-enzima, regenerando a enzima e formando um ácido carboxílico do tipo $\mathrm{R}_{1}-\mathrm{CO}-\mathrm{OH}(-\mathrm{b}) .{ }^{17}$

Para garantir que a reação de hidrólise em meio aquoso seja irreversível, são utilizadas altas concentrações de água $(55,5 \mathrm{~mol} / \mathrm{l}) .{ }^{17}$

a)

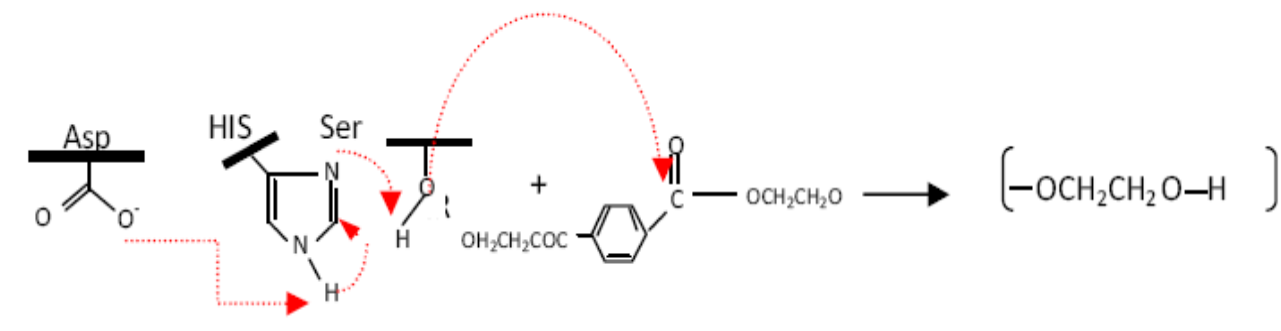

b)

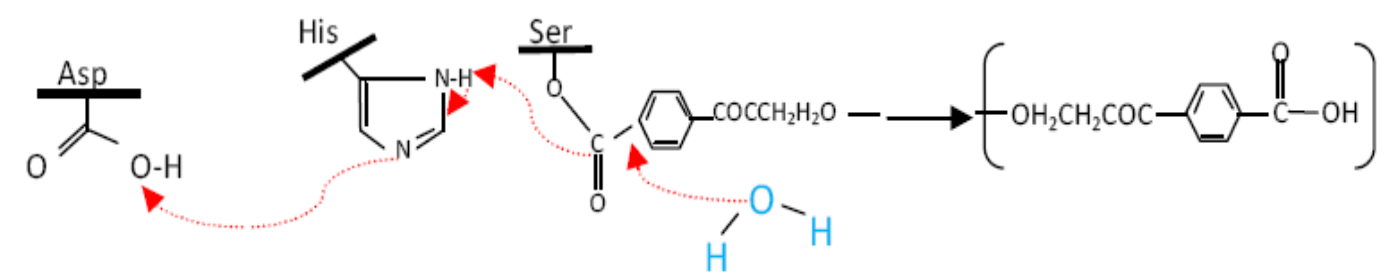

Figura 3 - Representação esquemática da hidrólise enzimática Fonte: Costa. ${ }^{17}$ 


\section{MATERIAL E MÉTODOS}

O trabalho foi desenvolvido no Laboratório de Tinturaria da Empresa Antex, no Município de Fazenda Rio Grande, no Estado do Paraná. Foram utilizadas amostras com 3 gramas de fibras 167/48-1TR100. A escolha dessa fibra está relacionada à dificuldade de tingimento em razão da alta cristalinidade ocorrida após estiramento.

O processo enzimático foi realizado com Lipase Triglicerol acil-hidrolases EC 3.1.1.3 de origem microbiana, obtida a partir da Cândida Rugosa Triacylglycerol Lipase (Sigma-Aldrich Chemical $\mathrm{Co}$ ), que possui atividade enzimática ótima entre 35 e $40^{\circ} \mathrm{C}$ e valores de $\mathrm{pH}$ entre 7 e 8 . O reagente alcalino utilizado foi hidróxido de sódio $\mathrm{NaOH}$ P.A. (Merck).

O hidrolisado alcalino foi obtido por meio da homogeneização da amostra de fibra em solução alcalina na concentração de $300 \mathrm{~g} / \mathrm{L}$, realizada em reator de vidro, encamisado e aberto de 250 $\mathrm{mL}$, à temperatura de $25^{\circ} \mathrm{C}$ e com agitação constante, durante 2 horas. Terminada a reação, as fibras hidrolisadas foram lavadas e acondicionadas por $24 \mathrm{~h}$ a $20^{\circ} \mathrm{C}$ e $65 \%$ de umidade.

Para obtenção do hidrolisado enzimático, a amostra de fibra foi homogeneizada com solução tampão na concentração de $50 \mathrm{mM}$ com controle de $\mathrm{pH}$ a 7,8, $10 \mathrm{mg} / \mathrm{mL}$ de enzima lipase, temperatura de $37^{\circ} \mathrm{C}$ controlada por banho termostatizado, em reator de vidro aberto de $250 \mathrm{~mL}$, com agitação constante. Transcorrido o tempo de 3 horas de reação, a enzima foi inativada termicamente por 15 minutos, e as fibras hidrolisadas foram lavadas e acondicionadas por $24 \mathrm{~h}$ a $20^{\circ} \mathrm{C}$ e $65 \%$ de umidade.

O tingimento foi realizado no equipamento AHIBA NUANCE DATACOLOR a temperatura de $135^{\circ} \mathrm{C}$ e pressão de 3,5 atm durante 2 horas em pH ácido com solução padrão de corante azul T. BGE, com corantes viola T. BL e azul HL-B. Foram utilizados auxiliares de tingimento Seragal (proporção 0,10 $\mathrm{gmL}^{-1}$ ), Seralub (proporção 0,10 $\mathrm{gmL}^{-1}$ ) e Tanasperse (proporção 0,10 gmL $\mathrm{gm}^{-1}$ ); o volume total de banho foi de $100 \mathrm{~mL}$.

Para a verificação da perda de massa, pela quebra das ligações, ocasionada pelos tratamentos alcalino e enzimático, as amostras foram devidamente pesadas em balança semianalítica da marca Mettler Toledo PG503-S, antes e após tratamento, com o devido tempo e condições de acondicionamento (secagem por 4 horas a $105^{\circ} \mathrm{C}$, acondicionadas por 7 dias a $20^{\circ} \mathrm{C}$ e $65 \%$ de umidade relativa). O procedimento de pesagem foi repetido até se obter peso constante entre as pesagens (considerou-se como peso constante diferenças entre as pesagens menores ou iguais a 5\%).

Para a determinação dos sítios ácidos, 30,0 mg de fibras parcialmente hidrolisadas foram misturados a 2,00 $\mathrm{mL}$ de hidróxido de sódio $\left(5,00 \times 10^{-2} \mathrm{molL}^{-1}\right)$ em tubo de ensaio, o qual foi agitado por 30 minutos. Em seguida, adicionaram-se 25,0 mL de água destilada, agitando-se esse conteúdo por mais 3 minutos. Uma alíquota de $10,0 \mathrm{~mL}$ foi coletada e titulada com solução de biftalato de potássio $1,50 \times 10^{-3} \mathrm{~mol} \mathrm{~L}^{-1}$, usando-se fenolftaleína como indicador.

As determinações da demanda química de oxigênio (DQO) foram realizadas segundo a metodologia do Standard Methods for the Examination of Water and Wastewater 4, na qual se recomenda a adição de $2 \mathrm{~mL}$ de amostra (filtrada em membrana de acetato de celulose 0,45 $\mu \mathrm{m}$ para DQO) e 2 
mL de amostra bruta (sem nenhuma filtração para DQO) nos tubos de DQO, aos quais são adicionados sais de prata e mercúrio com dicromato de potássio. Os tubos são aquecidos por $2 \mathrm{~h} \mathrm{a} 150{ }^{\circ} \mathrm{C} \mathrm{em}$ reatores de DQO. Após o resfriamento dos tubos, realizou-se a leitura da absorbância em espectrofotômetro ESPECTROQUANT NOVA 60. Empregando-se a curva de calibração feita com soluções de biftalato de potássio obteve-se o valor de DQO a partir das leituras de absorbância (branco e teste). As determinações desse parâmetro foram feitas em triplicata.

Para obtenção da correspondência de variação colorimétrica entre as amostras a avaliar a fixação do corante, as fibras foram analisadas em espectrofotômetro Datacolor DF100, de 400-700 nm, com intervalo de medição de $10 \mathrm{~nm}$, fonte de luz em flash xenon filtrada para iluminação D65, com reprodutividade de 0,05 Cielab $\Delta \mathrm{E}$ e repetitibilidade de $0,2 \Delta \mathrm{E}$.

Para visualização de mudanças morfológicas, foi realizada uma análise da topografia das fibras por microscópio eletrônico de varredura (MEV) da marca Philips, modelo XL30, com magnificações de 50X e 500X e tensão de aceleração de 10kV.

Foram realizados, segundo a norma ASTM D 882, ensaios de tração e alongamento, em que cinco corpos de prova foram tracionados a $10 \mathrm{~mm} \mathrm{~min}^{-1}$, em equipamento INSTRON modelo 4467 com célula de carga $10 \mathrm{~kg}$ e Lo de $20 \mathrm{~mm}$.

Foi realizada espectroscopia na região do infravermelho, utilizando o equipamento BRUKER, modelo VERTEX 70, com acessório de ATR com cristal de seleneto de zinco, na faixa espectral de 4000 a $400 \mathrm{~cm}^{-1}$, 64 varreduras e resolução de $4 \mathrm{~cm}^{-1}$, detector DLATGS.

A análise termodinâmico-mecânica foi conduzida utilizando-se o equipamento DMTA 242 NETZSCH no modo tração. A faixa de temperatura utilizada foi de 25 a $200{ }^{\circ} \mathrm{C}$ em atmosfera de nitrogênio, com frequência de força dinâmica de $50 \mathrm{~Hz}$ e taxa de aquecimento do forno de $3{ }^{\circ} \mathrm{C} / \mathrm{min}$.

\section{RESULTADOS E DISCUSSÃO}

A hidrólise alcalina proporcionou uma perda de massa de 4,39\%, como mecanismo de hidrólise ocorre pela ação do hidróxido na quebra da cadeia principal e formação do ácido tereftálico (AT), o qual é solubilizado na forma de tereftalato $\mathrm{TA}^{2-}(\mathrm{aq})$ permanecendo em meio aquoso, o que justifica a considerável variação de massa. Já na hidrólise enzimática, observou-se uma redução de massa de 0,06\%. A lipase catalisa a reação de hidrólise facilitando a interação do grupo éster com a água, gerando um grupo ácido carboxílico e álcool.

Na observação das curvas de DMTA de fibras de politereftalato de etileno, é possível obter informações a respeito do comportamento viscoelástico do sistema, por meio da análise de duas componentes: a contribuição viscosa e a elástica. A temperatura de transição vítrea do PET abrange uma ampla faixa $\left(67-140^{\circ} \mathrm{C}\right)$, sendo esta dependente da pureza, do grau de cristalinidade e do método de determinação. Para o PET amorfo, a $\mathrm{T}_{\mathrm{g}}$ aumenta com o aumento da cristalinidade. A transição vítrea 
observada pelo módulo de perda está próximo a $140{ }^{\circ} \mathrm{C}$. Esse valor elevado deve-se ao alto grau de cristalinidade e orientação do material.

No caso das fibras hidrolisadas, não há alterações significativas no comportamento mecânico da fibra em razão da temperatura (Figura 4).

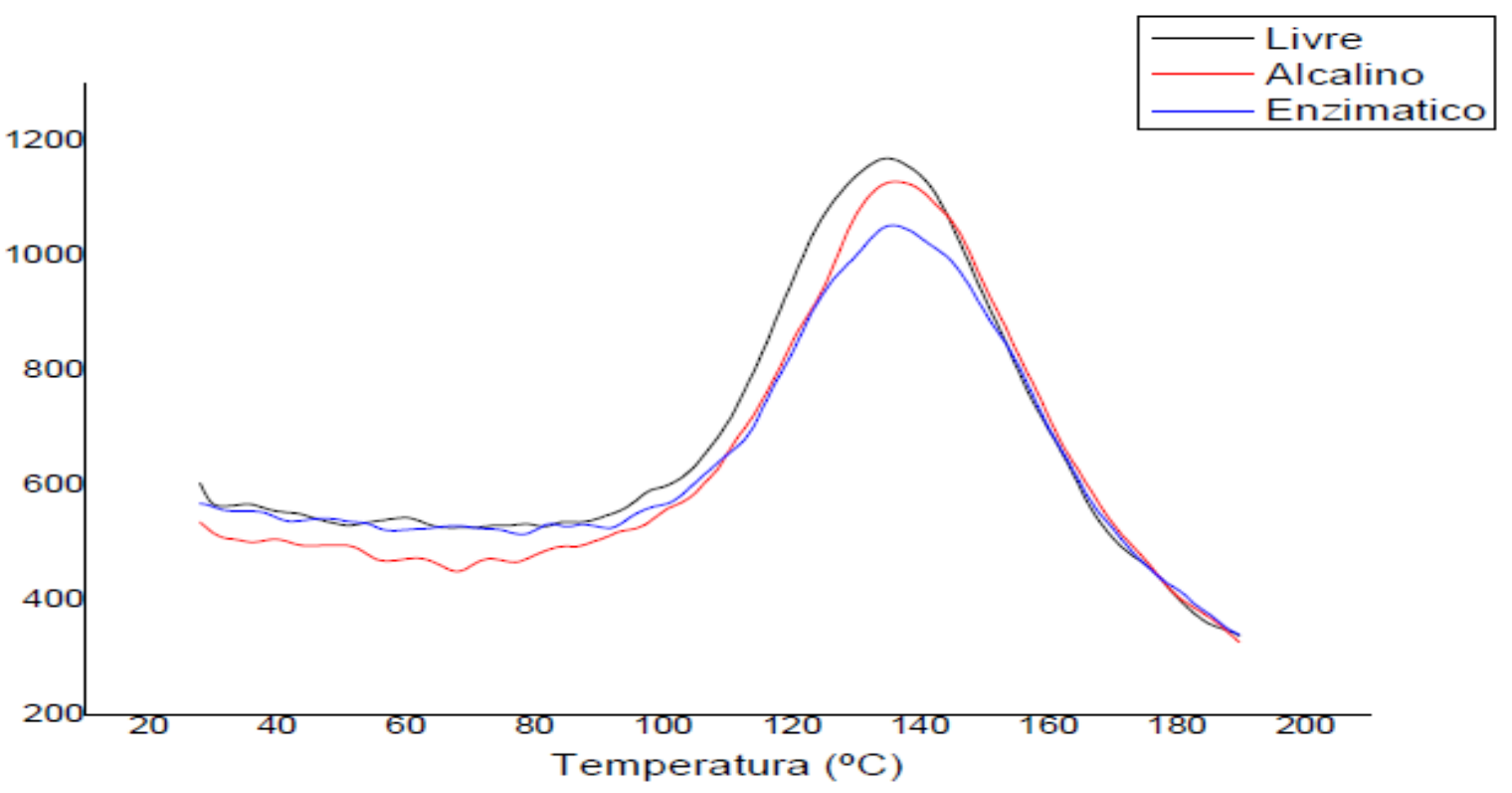

Figura 4 - Curvas de variação do módulo de perdas (E”) com a temperatura

Nota-se, conforme Tabela 1, que não ocorreu alteração significativa da temperatura de transição com os tratamentos realizados.

Tabela 1 - Resultados da variação da temperatura vítrea

\begin{tabular}{ll}
\hline Amostra & Temperatura $\left({ }^{\circ} \mathrm{C}\right)$ \\
\hline 1- Livre & 144,70 \\
2- Alcalino & 147,98 \\
3- Enzimático & 146,32 \\
\hline
\end{tabular}

O índice de grupos carboxílicos foi determinado por meio de titulação e análise por FTIR. Por titulação, observou-se que a fibra sem tratamento apresentava 0,148 $\mathrm{mmolg}^{-1}$, de sítios ácidos por grama de fibra. Após o tratamento alcalino, a fibra passou a apresentar $0,177 \mathrm{mmolg}^{-1}$, e a fibra tratada com enzimas apresentou 0,200 mmolg $^{-1}$ de sítios ácidos, ocorrendo um aumento de 19,59\% de sítios para $\mathrm{NaOH}$ e de 35,13\% para a enzima. Pela observância de mudanças ocorridas, por meio da titulação, foram obtidos os índices de carboxila para amostras com e sem tratamento, mediante espectros de FTIR, em virtude da detecção da banda em $1686 \mathrm{~cm}^{-1}$ (associada ao grupamento da carboxila) e a banda em $2974 \mathrm{~cm}^{-1}$ como referente. Como a região das carbonilas (entre 1680 e $1800 \mathrm{~cm}^{-1}$ ) apresenta mais de um tipo desse grupo químico (carbonilas de ácido, éster e antioxidante presente nas fibras), foi necessário o ajuste de curva por intermédio de Lorentzianas, com o auxílio do software Origin pro 
7.5, de modo a obter a área separadamente da carbonila referente ao grupo ácido carboxílico e, assim, calcular os índices de variação. Na há representação dos espectros na região da carboxila com o ajuste de curva por meio de Lorentzianas para a fibra sem tratamento, fibra tratada com enzima e fibra tratada com hidróxido de sódio, respectivamente.

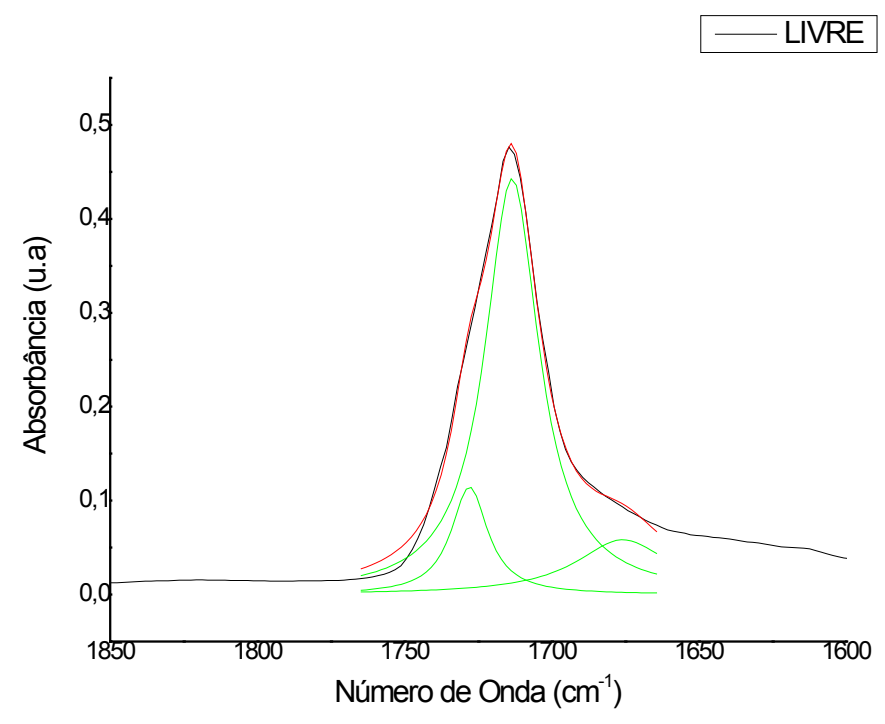

(A)
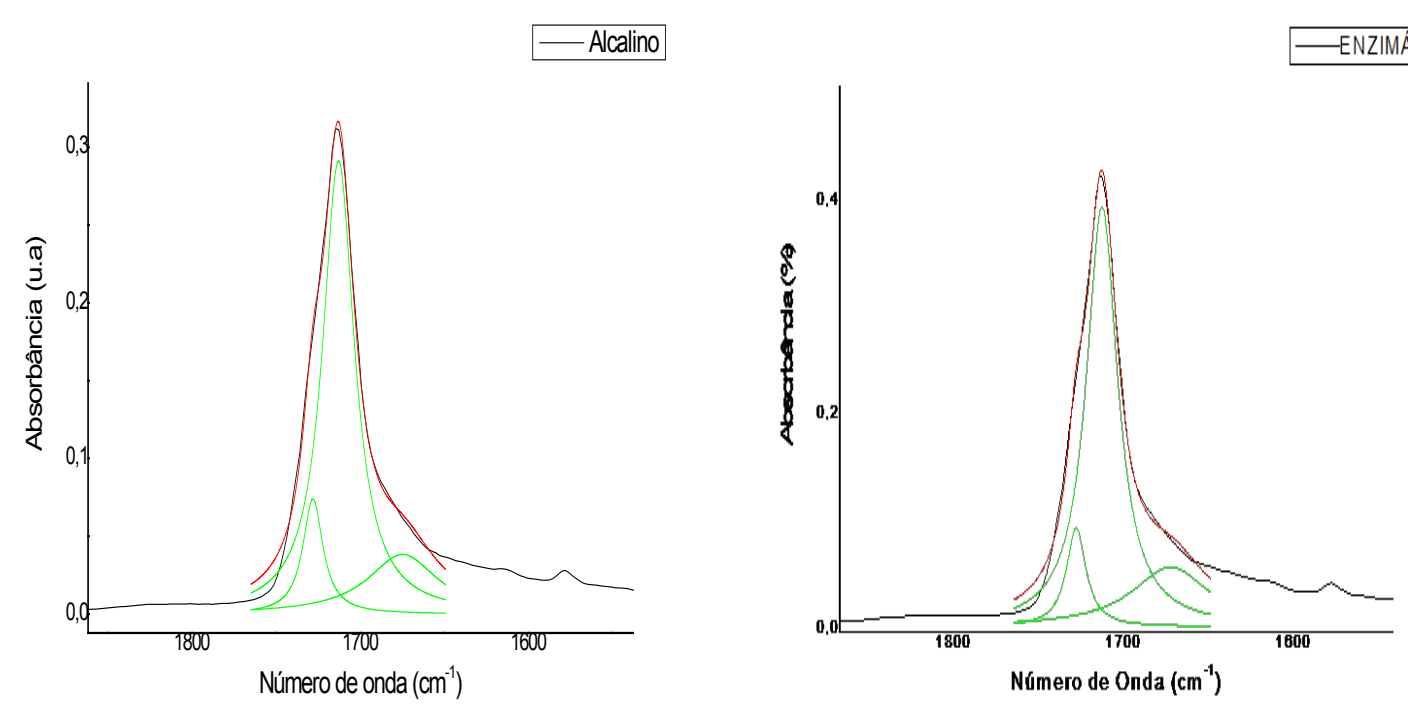

(B)

(C)

Figura 5 - Região do espectro FTIR e ajuste de curva por Lorentzianas, separando as áreas das diferentes carbonilas ${ }^{\ddagger}$

A fibra sem tratamento mostrou um índice de 0,90, com tratamento alcalino, 1,35, e com tratamento enzimático, 2,17. O aumento do índice de carbonila em $1686 \mathrm{~cm}^{-1}$ indica um aumento no

‡ Curvas em verde representam as áreas separadas, em preto, é o espectro obtido experimentalmente, e em vermelho, o ajuste resultante: A) Livre. B) Alcalino. C) Enzimática. 
índice do grupo carboxílico terminal entre as espécies tratadas e não tratadas, sendo possível constatar maior eficiência para o tratamento enzimático, corroborando os dados obtidos por titulação.

$\mathrm{Na}$ Figura 6 estão dispostas as micrografias da fibra livre e das fibras tratadas com hidróxido de sódio e lipase, sendo perceptível a presença de ranhuras e estrias longitudinais, que evidenciam a ocorrência de mudanças superficiais após tratamento alcalino e enzimático.

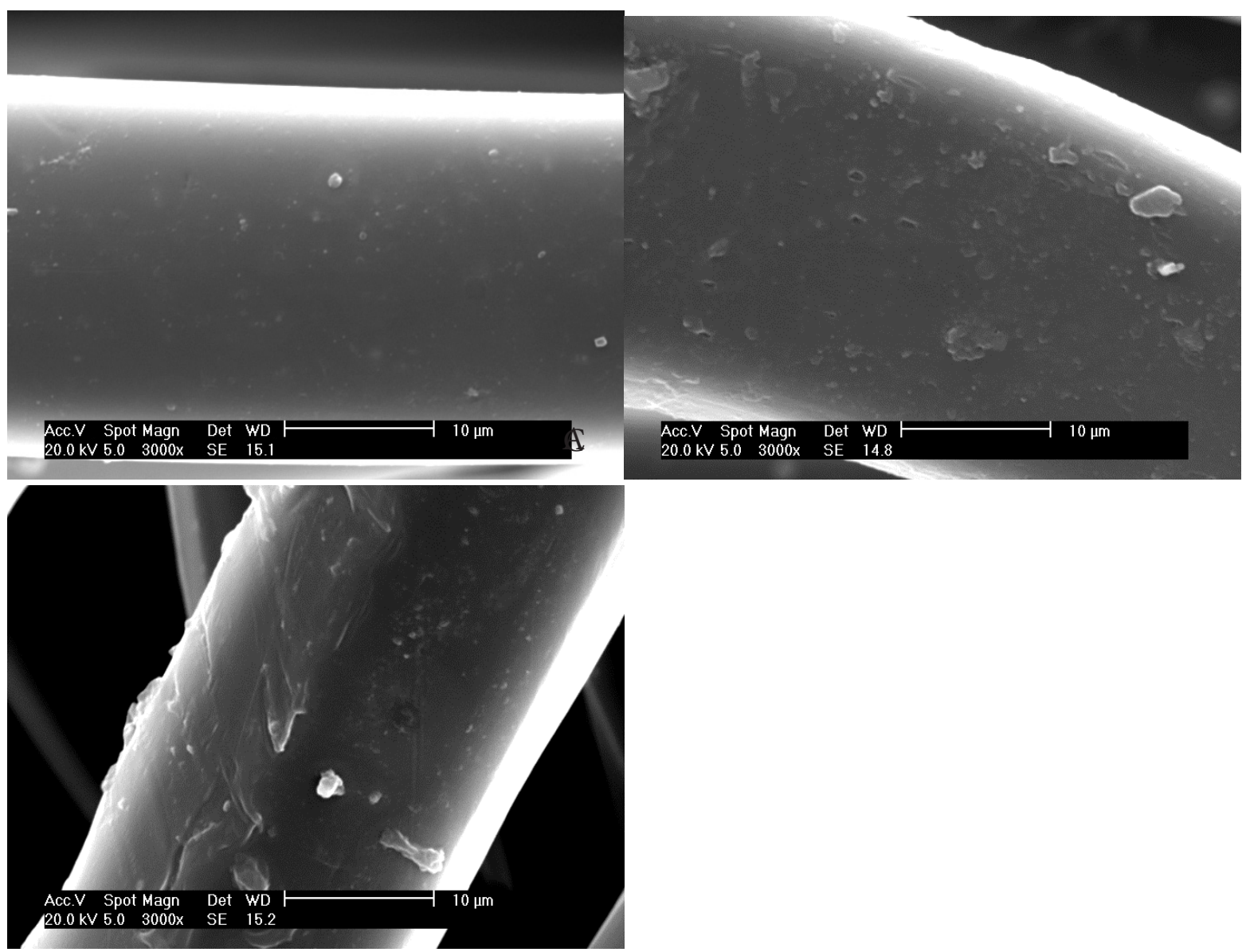

Figura 6 - Imagem obtida por MEV da superfície da fibra ${ }^{\S}$

Após a hidrólise, as fibras foram coloridas em conformidade com os padrões industriais relacionados ao tingimento por esgotamento, com o objetivo de avaliar as possíveis variações na carga orgânica do efluente gerado, decorrentes do aumento da hidrofilidade após hidrólise. Para garantir o tingimento uniforme, utilizou-se uma concentração padrão de corantes e insumos, os quais não foram totalmente convertidos, permanecendo em solução e gerando o designado efluente têxtil, o qual foi avaliado quanto ao parâmetro Demanda Química de Oxigênio (DQO). As variações resultantes do aumento da hidrofilidade superficial da fibra e consequente melhoria na fixação do corante foram comprovadas pela diminuição da carga orgânica do efluente gerado após tingimento e pela análise colorimétrica, a qual relaciona a fixação dos corantes. $\mathrm{O}$ efluente após tingimento da fibra não tratada

\footnotetext{
${ }^{\S}$ A) Fibra livre. B) Tratamento alcalino. C) Tratamento enzimático.
} 
apresentou $5031 \mathrm{mg} / \mathrm{mL}$ de DQO, enquanto os efluentes de tingimento para as fibras tratadas com álcali e com enzima apresentaram 4683 e $4734 \mathrm{mg} / \mathrm{mL}$ de DQO, respectivamente. Em relação à análise de solidez da cor, analisada por espectroscopia de reflectância, o efeito do tratamento alcalino das fibras de poliéster provocou a variação do valor de $\Delta \mathrm{E}^{\star}$, verificando que a amostra tingida é mais escura que a padrão com $\Delta \mathrm{L}^{\star}=-1,71$, mais vermelha $\left(\mathrm{Da}^{\star}=+1,85\right)$ e mais azul $\left(\mathrm{Db}^{\star}=-1,63\right)$, enquanto o tratamento enzimático originou uma fibra mais clara $\left(\Delta \mathrm{L}^{*}=+0,52\right)$, mais verde $\left(\mathrm{Da}^{*}=-0,45\right)$ e mais amarela $\left(\mathrm{Db}^{*}=+1,67\right)$. Em decorrência das variações ocorridas na análise da qualidade do tingimento, foi necessária uma correção na receita de tingimento, que proporcionou economia de insumos. Essa variação de cor está em conformidade com a diminuição da Demanda Química de Oxigênio, correspondendo com a maior fixação dos corantes.

Os materiais utilizados na confecção têxtil devem possuir características mecânicas iniciais para que suportem a tração durante tecelagem de tecidos. ${ }^{5} \mathrm{Na}$ estão dispostos os dados referenciais do ensaio de tração da fibra tratada com hidróxido de sódio 300 g/L e com enzima lipase, em comparação às fibras não tratadas.

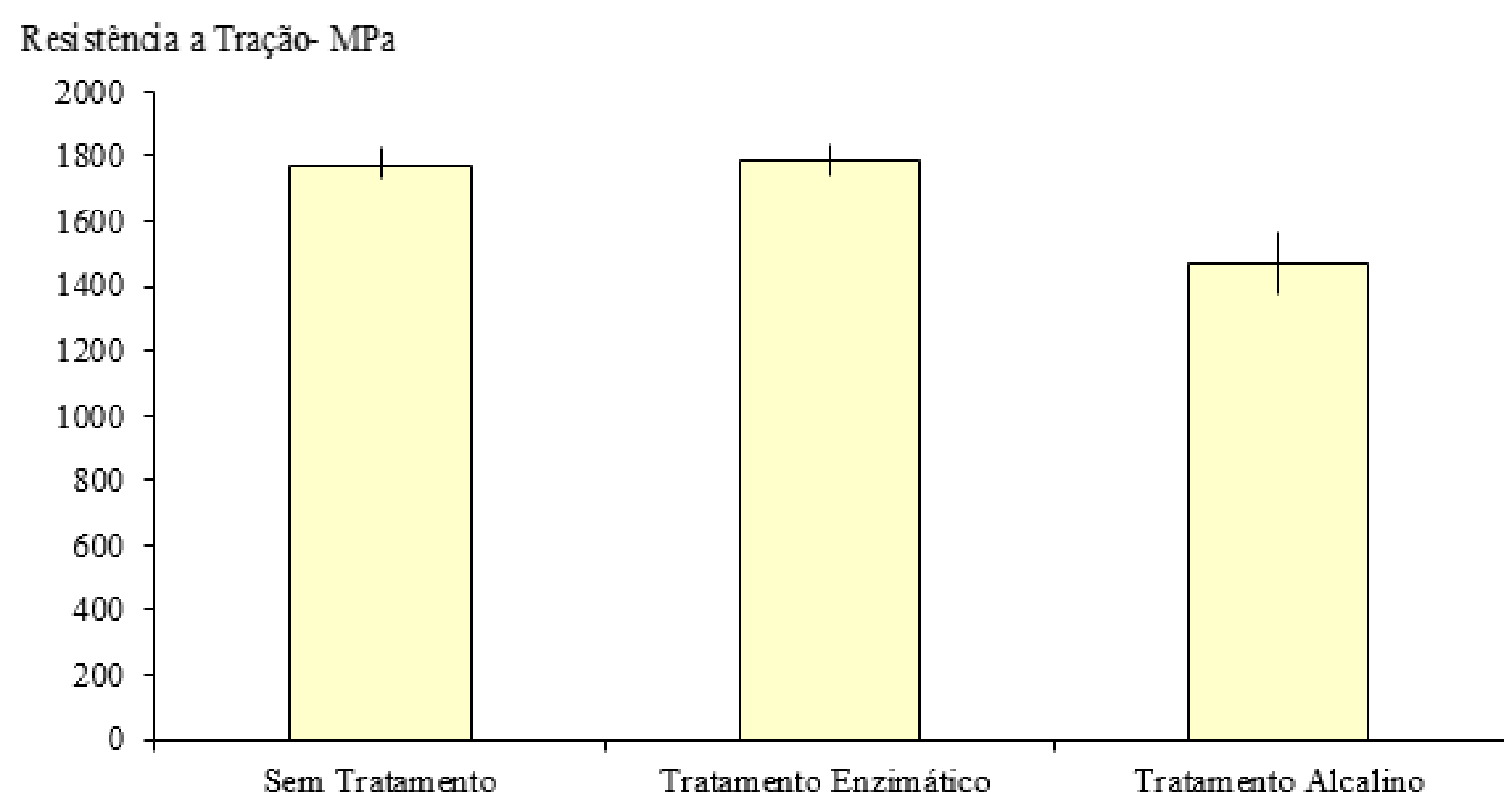

Figura 7 - Variação da resistência mecânica com os tratamentos alcalino e enzimático

Os resultados mostram que a maior variação foi obtida com o tratamento alcalino, indicando maior agressividade deste, considerando-se os dados que correspondem aos obtidos na análise de perda de massa. Há uma diminuição de, aproximadamente, $17 \%$ da resistência da fibra após tratamento alcalino, já o tratamento enzimático não confere variações significativas na resistência da fibra. A variação numérica da resistência à tração das fibras está relacionada na Tabela 2. 
Tabela 2 - Variação da resistência mecânica das fibras tratadas

\begin{tabular}{cc}
\hline Tratamento & Variação em relação à fibra padrão \\
\hline Alcalino & $17,2 \pm 3,09 \%$ \\
Enzimático & $0,65 \pm 0,04 \%$ \\
\hline
\end{tabular}

Na Figura 8, estão dispostos os dados do ensaio de tração da fibra tratada com hidróxido de sódio 300 g/L e enzima lipase em comparação com a fibra livre, após tingimento. O tingimento por esgotamento acontece com variação de temperatura, o que pode comprometer as características mecânicas tanto da fibra livre quanto das fibras tratadas.

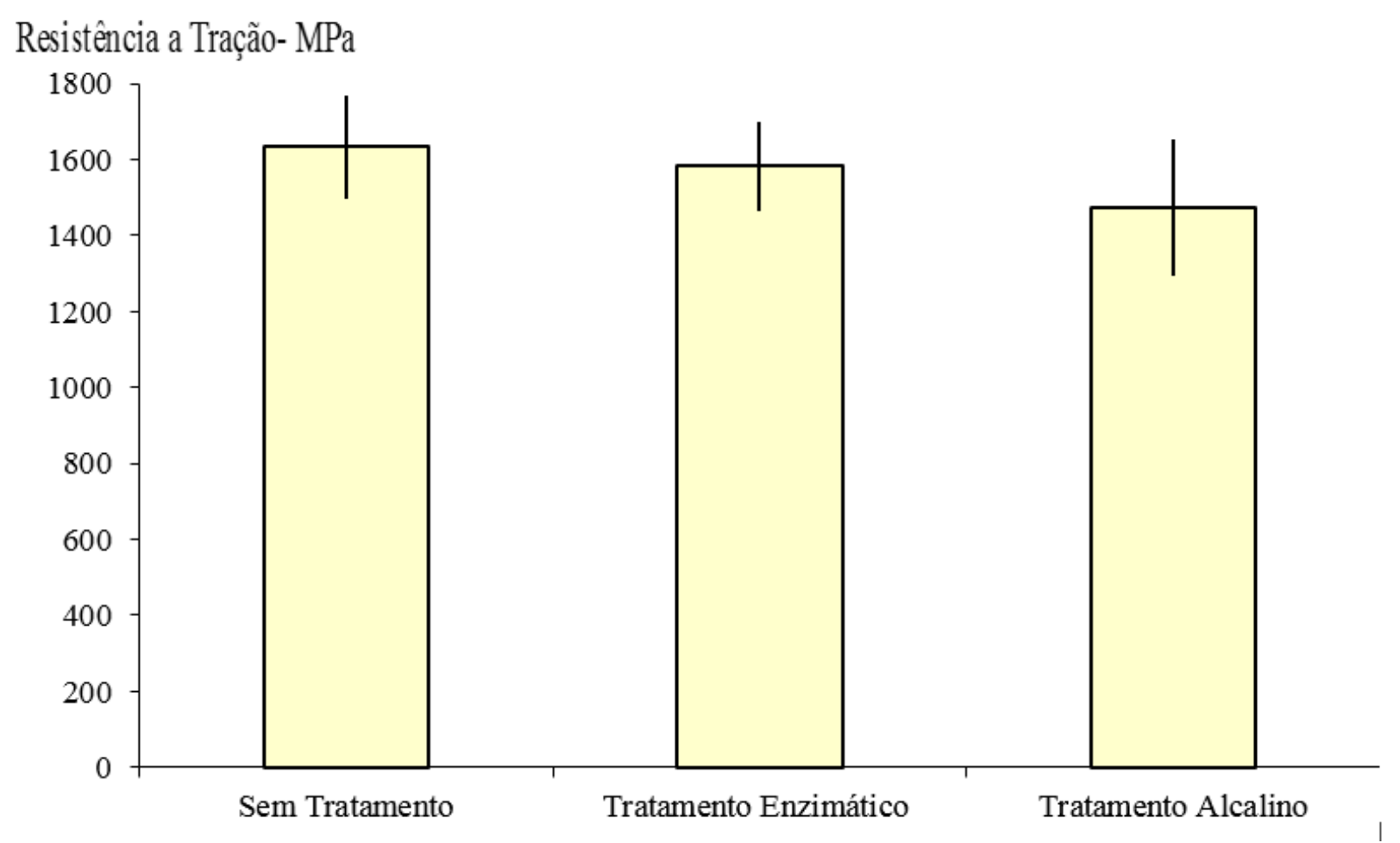

Figura 8 - Variação da resistência mecânica das fibras tratadas e tingidas

A distinção entre os tratamentos diminuiu significativamente, conforme pode ser constatado na Tabela 3. As fibras com tratamento alcalino após tingimento (temperatura de $130{ }^{\circ} \mathrm{C}$ ) apresentam variação menor da resistência mecânica para o tratamento alcalino, sendo de aproximadamente $9,80 \%$, e o tratamento enzimático aumentou a variação para, aproximadamente, $3 \%$.

Tabela 3 - Variação da resistência à tração das fibras tratadas e tingidas

\begin{tabular}{cc}
\hline Tratamento & Variação em relação à fibra padrão \\
\hline Alcalino & $9,80 \pm 3,60 \%$ \\
Enzimático & $3,15 \pm 0,89 \%$ \\
\hline
\end{tabular}


Na avaliação da resistência à tração após o tingimento, a fibra sem tratamento apresentou o valor de $1633 \mathrm{MPa}$ contra $1473 \mathrm{MPa}$ e $1582 \mathrm{MPa}$ das fibras tratadas com álcali e enzima, respectivamente, comprovando a influência do tingimento nas propriedades mecânicas e salientando que a fibra que passou pela hidrólise enzimática teve valor maior que a fibra de hidrólise alcalina, confirmando que o tratamento enzimático é menos agressivo.

\section{CONCLUSÃO}

Os resultados dos tratamentos alcalinos realizados correspondem aos já descritos na literatura. Esses resultados apontam para a possibilidade de melhorias nas propriedades de tingimento e umectação do poliéster sem causar grande perda de peso e resistência do material.

No entanto, comparativamente, o tratamento enzimático com lipase não provocou alteração na massa, mostrando-se, nesse caso, menos agressiva que o tratamento alcalino, pois as amostras apresentaram pequenas variações na cristalinidade e um aumento na incorporação dos corantes, evidenciado pela redução do DQO de 7\%. Considerando-se que a resistência mecânica não apresentou alterações significativas no caso do tratamento enzimático, no tratamento alcalino foram obtidas variações de, aproximadamente, 10\%, evidenciando-se um tratamento bastante agressivo.

Relacionando o tratamento enzimático à eficiência na geração de sítios ácidos, o procedimento apresenta-se bastante viável, da mesma maneira em relação à diminuição do DQO.

Portanto, o uso de enzima lipase em um processo que antecede o tingimento diminui o consumo de corantes e insumos de tingimento.

\section{REFERÊNCIAS}

1. Sanin LBB. A indústria têxtil e o meio ambiente. In: Anais do XIV Congresso da FLAQT, 1997; Caracas. Caracas; 1997. p. 13-34.

2. Needles HL, Walker C. Flammability characteristics of lightweight cellulosic and polyester-cellulosic blend fabrics. Journal of Fire Sciences. 1985; 3:461-71. doi: 10.1177/073490418500300606

3. Santos WLF. Modificação e tingimento de filmes e malhas de poli(tereftalato de etileno) [tese]. Maringá: Universidade Federal de Maringá; 2005. [acesso em 2014 out 04]. Disponível em: http:// www.dominiopublico.gov.br/pesquisa/DetalheObraForm.do? select action $=\&$ co obra $=92680$

4. Mocherla K. Morphology of uniaxially and oriented poly (ethylene terephthalate). Journal of Polymer Science: Polymer Physics Edition. 1973; 11(9):1779-91. doi: 10.1002/pol.1973.180110910

5. Vicunha. Têxtil - Manual técnico de poliéster [catálogo]. São Paulo; 2008. 
6. Dolzan NI. Tratamento de fibras sintéticas com corante disperso [dissertação] [Internet]. Florianópolis: Universidade Federal de Santa Catarina; 2004. [acesso em 2014 set 04]. Disponível em: https://repositorio.ufsc.br/xmlui/handle/123456789/88042

7. Rajaguru P, Fairbairn LJ, Ashby J, Willingion MA, Turner S, Woolford LA et al. Genotoxicity studies on the azo dye direct red 2 using the in vivo mouse bone marrow micronucleus test. Mutation Research. 1999; 444:175-80. doi: 10.1016/S1383-5718(99)00081-9

8. Paoli MA. Degradação e estabilização de polímeros. 1. ed. São Paulo: Artliber; 2008. [acesso em 2014 jul 04]. Disponível em: http://www.chemkeys.com/blog/wp-content/uploads/2008/09/polimeros.pdf

9. Sander EM, Zeronian SH. Analysis of the moisture related properties of hydrosed polyester. Journal Applied Polymer Science. 1982; 27:4471-91. doi: 10.1002 / app.1982.070271135

10. Lewin M. Fibre chemistry, handbook of fibre science technology. New York: Mercel Dekker, 1985. v. 4.

11. Mancini SD, Zenin M. Influência de meios reacionais na hidrólise de PET pós-consumo. Polímeros: Ciência e Tecnologia [Internet]. 2002 [acesso em 2014 nov 16]; 12(1):34-40. Disponível em: http://www.scielo.br/pdf/po/v12n1/9880.pdf

12. Rosmarinho MG, Jardim E, Ferreira LG, Araújo HM, Lago MR, Moura CFC. Hidrólise parcial da superfície do polyethylene terephthalate (PET): transformando um rejeito em um material de troca catiônica para aplicação ambiental. Química Nova [Internet]. 2009 [acesso em 2014 set 20]; b32(6):s1-s2. Disponível em: http://dx.doi.org/10.1590/S0100-40422009000600055

13. Vogel AI. Química Orgânica Qualitativa. 6. ed. Rio de Janeiro: Livros Técnicos Científicos; 2002.

14. Faber K. Biotransformation in Organic Chemistry. 4. ed. Berlin: Springer-Verlag; 2000. [acesso em 2014 jul 16]. Disponível em: https://books.google.com.br/books?hl=pt-BR\&lr=\&id=USnH4RGy ORYC\&oi=fnd\&pg=PR3\&dq=FABER + +K.+Biotransformation + in + Organic + Chemistry $+4+$ ed. + Ber lin:+Springer-verlag,+2000.\&ots=UU33pWLWUv\&sig=kMeC8VIHCggCrVTEHDGMEuMsTCU\#v =onepage\&q\&f=false

15. Jaeger KE, Eggert T. Lipases for biotechnology. Current Opinion in Biotechnology. 2002; 13:3907. doi:10.1016/S0958-1669(02)00341-5

16. Cruz Júnior A. Imobilização de lipase de candida antarctica bem quitosana para obtenção de biodiesel por transesterificação do óleo de mamona [dissertação] [Internet]. Florianopolis: Universidade Federal de Santa Catarina; 2007. [acesso em 16 maio 2014]. Disponível em: https://repositorio. ufsc.br/xmlui/handle/123456789/90127

17. Costa CE. Biotransformação na obtenção de hidroxi-selenetos e hidroxi-teluretos quirais [tese]. São Paulo: Universidade de São Paulo; 2007. 
